University of Nebraska - Lincoln

DigitalCommons@University of Nebraska - Lincoln

$10-2012$

\title{
Serotonin System Gene Polymorphisms Are Associated with Impulsivity in a Context Dependent Manner
}

\author{
Scott F. Stoltenberg \\ University of Nebraska-Lincoln, sstoltenberg2@unl.edu \\ Christa C. Christ \\ University of Nebraska-Lincoln \\ Krista B. Highland \\ University of Nebraska-Lincoln, khighland@dvcipm.org
}

Follow this and additional works at: https://digitalcommons.unl.edu/psychfacpub

Part of the Genetics Commons, and the Psychology Commons

Stoltenberg, Scott F.; Christ, Christa C.; and Highland, Krista B., "Serotonin System Gene Polymorphisms Are Associated with Impulsivity in a Context Dependent Manner" (2012). Faculty Publications, Department of Psychology. 998.

https://digitalcommons.unl.edu/psychfacpub/998

This Article is brought to you for free and open access by the Psychology, Department of at DigitalCommons@University of Nebraska - Lincoln. It has been accepted for inclusion in Faculty Publications, Department of Psychology by an authorized administrator of DigitalCommons@University of Nebraska - Lincoln. 


\title{
Serotonin System Gene Polymorphisms Are Associated with Impulsivity in a Context Dependent Manner
}

\author{
Scott F. Stoltenberg, Christa C. Christ, and Krista B. Highland
}

Behavior Genetics Laboratory, Department of Psychology, University of Nebraska-Lincoln, Lincoln, Nebraska, USA

Corresponding author - Scott F. Stoltenberg, Behavior Genetics Laboratory, Department of Psychology, University of Nebraska-Lincoln, 238 Burnett Hall, P.O. Box 880308, Lincoln, NE, 68588-0308, USA, telephone 402-472-7861, fax 402-472-4637, email sstoltenberg2@unl.edu

\begin{abstract}
Impulsivity is a risk factor for adverse outcomes and characterizes several psychiatric disorders and risk for suicide. There is strong evidence that genetic variation influences individual differences in impulsivity, but the details are not yet understood. There is growing interest in better understanding the context dependency of genetic effects that is reflected in studies examining gender specificity, gene $\times$ environment interaction and epistasis (gene-gene interaction). In a cross-sectional study we examined whether polymorphisms in six serotonin system candidate genes and the experience of early life trauma (age 0-12) were associated with individual differences in impulsivity in a nonclinical sample of Caucasian university students $(N=424)$. We specifically tested potential gender specific, gene-gene, and gene $\times$ environment (early life trauma) effects. In our main analyses with Barratt Impulsiveness Scale (BIS-11) total score, there were significant (i.e., $p<.01$ and False Discovery Rate $<.10$ ) interactions between (1) gender and TPH2 (rs1386483) genotype; (2) gender and HTR2A (rs6313) genotype; and epistatic interactions among (3) 5-HTTLPR and MAOA uVNTR; (4) 5HTTLPR and rs6313 and (5) HTR1B (rs6296) and rs6313 genotypes. Our results strongly support the explicit investigation of context-dependent genetic effects on impulsivity and may help to resolve some of the conflicting reports in the literature.
\end{abstract}

Keywords: 5-HTTLPR, HTR1B (rs6296), HTR2A (rs6313), MAOA uVNTR, TPH2 (rs1386483) 
StoltenberG, Christ, AND Highland,

\begin{abstract}
Abbreviations: 5-HT, serotonin; 5-HTTLPR, serotonin transporter linked polymorphic region polymorphism; ADHD, attention deficit hyperactivity disorder; AGRS, Aggregate Genetic Risk Score; BIS-11, Barratt Impulsiveness Scale, version 11; COMT, catechol-O-methyl transferase; FDR, False Discovery Rate; GLM, general linear model; $G \times$ E, genotype by environment interaction; HTR1A, serotonin receptor 1A; HTR1B, serotonin receptor 1B; HTR2A, serotonin receptor 2A; IRB, institutional review board; MAOA,monoamine oxidase A; SERT, serotonin transporter; SLC6A4, serotonin transporter; SNP, single nucleotide polymorphism; TAQ, Traumatic Antecedent Questionnaire; TPH2, tryptophan hydroxylase 2; VNTR, variable number tandem repeat.
\end{abstract}

\title{
1. Introduction
}

Impulsivity is a multidimensional psychological construct generally characterized by acting quickly and without sufficiently considering the consequences (Evenden, 1999). Impulsivity is associated with increased risk for a variety of adverse outcomes, such as money mismanagement (Hamilton and Potenza, 2012) and mortality risk (Blonigen et al., 2011), and characterizes certain psychiatric disorders such as alcohol use disorders (Dick et al., 2010), eating disorders (Waxman, 2009), obsessive compulsive disorder and impulse control disorders (Fineberg et al., 2010), attention deficit and hyperactivity disorder (Kuntsi et al., 2006), bipolar disorder (Swann, 2010), and risk for suicide (Giegling et al., 2009) as well as conditions such as obesity (Barry et al., 2009) and problem gambling (Shenassa et al., 2012). In addition, the capacity to control one's behavior represents an important aspect of legal responsibility (Barratt and Felthous, 2003). Impulsivity appears to represent a critical mediator of general risk for problems resulting from rash responding and deficits in behavioral inhibition, planning, and so on and may serve as an endophenotype for several behavioral disorders (Fineberg et al., 2010; Robbins et al., 2012). Therefore, a more detailed understanding of the factors associated with the trait of impulsivity is likely to have farreaching effects. The study reported here focuses on the potentially moderating effects of context (i.e., gender, genetic, early life experience) on associations between multiple genetic polymorphisms in a single neurotransmitter system and impulsivity.

The serotonin (5-HT) neurotransmitter system plays an important role in impulsivity that is complex and not yet fully characterized (Pattij and Vanderschuren, 2008). However, there is convergent evidence that low 5-HT neurotransmission is generally associated with impulsivity (Winstanley, 2011). The results of pharmacological studies indicate that serotonergic agents can have different effects depending on several factors including their targets (e.g., receptor type), the type of impulsive behavior in question, and the sex of the subject (Pattij and Vanderschuren, 2008; Winstanley, 2011). Such complexity has retarded the development of a general theory of serotonin function, though a recent hypothesis regarding serotonin's role in the drive to withdraw from dangerous, aversive, or high stimulation environments appears to directly address the context dependency of serotonin's diverse effects (Tops et al., 2009). According to the withdrawal hypothesis, serotonergic hypofunction, which could result from certain experiences (e.g., early life adversity) or genotype combinations (e.g., in the serotonin system and in other neurotransmitter systems), would produce a dysfunction in the tendency to withdraw from or to avoid certain stimuli or environments (i.e., impulsivity). 
STOLTENBERG, CHRist, AND Highland,

Genetic variation accounts for a significant and relatively stable proportion of variance in impulsivity, as measured by the Barratt Impulsiveness Scale, in populations; and some of the genetic influence appears to be specific to different impulsivity facets (Niv et al., 2012). Genetic variation also accounts for variance in impulsivity when assessed using other measures, and these effects are observed across age groups and stronger in men than in women (Bezdjian et al., 2011). Impulsivity is a classic quantitative trait that is likely to be influenced by many genes with small, context dependent effects; and it is likely that a systems biology approach will be necessary to understand its genetic architecture (Mackay et al., 2009).

Genes that affect 5-HT system function are excellent candidates for association with impulsivity. In the following paragraphs we briefly describe six candidate genes in the serotonin system that are critical components of serotonin neurotransmission and present some evidence that polymorphisms in these genes are associatedwith individual differences in impulsivity or impulsivity-related traits. When available, we present evidence that particular associations are moderated by gender, early life experiences, or by other genotypes.

Tryptophan hydroxylase (TPH; EC 1.14.16.4) is the rate-limiting enzyme in the biosynthesis of 5-HT. In neurons, the TPH2 gene (12.q.21.1) codes for TPH. Diagnoses or conditions related to impulsivity such as borderline personality disorder and aggression (PerezRodriguez et al., 2010); and suicide risk (Lopez de Lara et al., 2007; Zupanc et al., 2011) are associated with TPH2 polymorphisms. Nominal associations have been identified with TPH2 polymorphisms and cognitive and overt aggressive impulsivity in children with attention-deficit/hyperactivity disorder (Oades et al., 2008). TPH2 polymorphisms are also associated with risk taking behavior in a gambling task (Juhasz et al., 2010), executive function (Reuter et al., 2007) and response inhibition (Stoltenberg et al., 2006). A polymorphism of interest, rs1386483, is located in an intron and is not known to affect TPH2 expression or function, but the minor allele (A) has been hypothesized to be associated with reduced 5-HT synthesis (Stoltenberg et al., 2006).

The 5-HT transporter (SERT) is an integral membrane protein that removes 5-HT from the synapse, transporting it into the intracellular compartment where it is then either repackaged into a vesicle for rerelease or degraded. Upstream from the transcription start site of the SERT gene (SLC6A4; 17q11.2) is the most commonly studied polymorphism in behavioral and psychiatric genetics, 5-HTTLPR (Murphy and Moya, 2011). Together with the 5-HTTLPR, another polymorphism, rs25531, appears to affect the expression of SERT (Hu et al., 2005; Nakamura et al., 2000). Homozygosity for the L allele of 5-HTTLPR and the A allele of rs25531 (LA/LA) is associated with increased SERT transcriptional efficiency, relative to carriers of an S allele or an LG allele. Higher SERT transcriptional efficiency should result in increased 5-HT reuptake and reduced 5-HT availability in the synapse. Recent reports of the influence on 5-HTTLPR on impulsivity appear to be somewhat contradictory. In one study the 5-HTTLPR genotype interacted with serious life events (such as rape) on impulsivity such that patients with borderline personality disorder who have experienced serious life events with the $S$ allele have decreased impulsivity and those that have the L allele have increased impulsivity (Wagner et al., 2009). However, in a nonclinical population, those who experienced higher levels of childhood adversity with the $S$ allele had 
StoltenberG, Christ, AND Highland,

increased impulsivity in response to emotions (Carver et al., 2011). There are clearly differences in the study populations as well as in the impulsivity assessment in these two studies. It does appear, however, that the effects of 5-HTTLPR on impulsivity may be sensitive to the environmental (Paaver et al., 2008) and biochemical/genetic (Paaver et al., 2007) context.

Monoamine oxidase A (MAOA; EC 1.4.3.4) is the primary enzyme involved in 5-HT degradation. In males with ADHD, MAOA SNPs are associated with impulsivity (Liu et al., 2011). A common variable number tandem repeat polymorphism (uVNTR) is located upstream of the structural gene for MAOA (Xp11.3). The number of repeats is associated with MAOA transcriptional efficiency (in vitro) such that 3.5 and 4 repeats have 2-10 times higher transcriptional efficiency than 3 and 5 repeats (Huang et al., 2004; Sabol et al., 1998). Increased levels of MAOA in vivo should result in reduced 5-HT availability. In those with major depressive disorder, the 4-repeat (high function) allele of the MAOA uVNTR is associated with increased risk for suicide attempts (Lung et al., 2011). The effects of MAOA genetic polymorphisms on risk for impulsive, violent crime appear to be moderated by heavy drinking and exposure to childhood physical abuse in male Finnish alcoholic violent offenders (Tikkanen et al., 2010).

$5-\mathrm{HTR}_{1 \mathrm{~A}}$ receptors are somato-dendritic autoreceptors that inhibit serotonergic neurotransmission, as well as postsynaptic targets, depending on their location. Genetic polymorphisms in HTR1A (5q11.2-q13) have been associated with individual differences in impulsivity. In particular, a common promoter region polymorphism (C-1019G, rs6295) that alters a binding site for a transcriptional repressor (Lemonde et al., 2003) appears to be associated with self-report measures of impulsivity (Benko et al., 2010) and response inhibition in a context dependent manner (Beste et al., 2011) as well as response-related processes reflected in event-related potentials (Beste et al., 2010). The $G$ allele appears to be associated with reduced expression of HTR1A, which would be associated with reduced feedback inhibition of the 5-HTR1A autoreceptors (Lemonde et al., 2003). Therefore, the C allele would likely be associated with lower synaptic 5-HT availability.

5 -HTR1B receptors are terminal autoreceptors that regulate quantal release of 5-HT as well as postsynaptic heteroreceptors, depending on their location. Genetic polymorphisms in HTR1B (6q13) have been associated with individual differences in impulsivity. Some studies (New et al., 2001), but not all (Rujescu et al., 2003), have found associations with rs6296 (also known as G861C) and suicide. Although the G961C polymorphism does not result in an altered amino acid sequence (i.e., it is a silent substitution), it is in linkage disequilibrium with other polymorphisms including the HTR1B microRNA binding site polymorphism rs13212041 (also known as A1997G (Conner et al., 2010)) that recently has been associated with impulsivity (Varga et al., 2012). The C allele of rs6296 is part of a low expression haplotype, which is likely to result in reduced feedback inhibition of the 5HTR1в terminal autoreceptors and/or reduced availability of 5-HTR1в heteroreceptors (Conner et al., 2010).

5-HT2A receptors are postsynaptic targets of 5-HT. Nonhuman animal model pharmacological studies strongly implicate the 5-HT2 A receptors in impulsivity (Winstanley, 2011). Genetic polymorphisms in HTR2A (13q14-q21) have been associated with individual differences in impulsivity, albeit with mixed results. Alcohol-dependent patients who 
StoltenberG, Christ, AND Highland,

were $\mathrm{C}$ allele homozygotes of rs6313 (also known as T102C) had significantly higher impulsivity scores than T allele carriers (Jakubczyk et al., 2012). The rs6313 polymorphism is in nearly complete linkage disequilibrium with rs6311 (also known as A1438G), with the rs6313 C allele in linkage disequilibrium with the rs6311 A allele, which is associated with reduced 5-HTR2A densities (Parsons et al., 2004). Reduced densities of 5-HTR2A would presumably reduce 5-HT neurotransmission. Homozygotes for the C allele of rs6313 made more commission errors than those with the other genotypes on a test of behavioral control (Bjork et al., 2002). However in another study, rs6313 genotype interacted with the catechol$\mathrm{O}$-methyltransferase (COMT) Val158Met polymorphism such that $\mathrm{T}$ allele homozygotes who were also Met allele homozygotes for COMT had higher impulsivity (i.e., subscale of Novelty Seeking) scores than those who were Val allele carriers (Salo et al., 2010). Such patterns of results reinforce the notion that the effects of particular genetic variants on impulsivity are sensitive to context.

Given the apparent multilocus architecture of impulsivity, it is reasonable to seek evidence for epistatic interaction among system components (Templeton, 2000), especially among components that are known to biologically interact. Control system models suggest that epistatic interaction among 5-HT system components is likely to play a role in aspects of 5-HT function (Stoltenberg, 2005) which, in turn, may be associated with impulsivity (Stoltenberg and Nag, 2010). Genetic effects on complex psychological or psychiatric traits are increasingly considered to be context dependent (Carver et al., 2008; Caspi et al., 2010; Uher et al., 2011), so it seems important to design studies with a goal of better characterizing both epistatic and $\mathrm{G} \times \mathrm{E}$ interactions and gender specific effects.

This study was designed to replicate and extend the findings of our earlier work on associations of 5-HT system genetic variants on impulsivity (Stoltenberg and Nag, 2010; Stoltenberg et al., 2006). We attempted to determine (1) whether there are associations between important candidate polymorphisms in the 5-HT system and impulsivity, and in supplemental analyses and (2) whether the patterns of association are the same for different facets of impulsivity. We focused on well-studied candidate gene polymorphisms in the 5-HT system and specifically tested for epistatic interactions among these candidate polymorphisms, for $\mathrm{G} \times \mathrm{E}$ interactions with reported early life trauma and for gender specific effects (Williams et al., 2003). The presence of such interactions (i.e., context dependency) may help to explain the relatively common lack of replication of main effects in candidate gene association studies.

\section{Materials and methods}

\subsection{Participants}

Students from a small Midwestern university $(\mathrm{N}=477)$ were recruited via posters and brief in-class presentations. The study was approved by the local IRB. Participants provided informed consent and were recompensed $\$ 20$ for approximately two hours of their time. Participants completed questionnaires assessing early life experiences, impulsivity and health-risk behaviors, computer tasks assessing impulsivity and decision-making, and donated buccal cell samples for genotyping. Only data directly relevant to the investigation of associations among certain serotonin system genetic polymorphisms, gender, early life 
STOLTENBERG, CHRist, AND Highland,

trauma, and self-reported impulsivity are reported here; other analyses are reported elsewhere (Stoltenberg et al., 2011a, 2011b, 2012). The final data set $(\mathrm{N}=424)$ comprised data from participants with no missing data for variables of interest and who were self-reported Caucasians $(92.0 \%$ of entire sample) to reduce the risk of population stratification. The mean age of the sample was $22.47(\mathrm{SD}=6.15)$ with $64.9 \%$ of the sample being female and $85.4 \%$ between the ages of 18 and 25 .

\subsection{Measures}

\subsubsection{Barratt Impulsiveness Scale}

The Barratt Impulsiveness Scale (BIS-11) is a 30-item self-report instrument that uses a 4-point Likert scale from Rarely/Never to Almost Always (Patton et al., 1995). Three subscales assess Motor ("I act on the spur of the moment"), Attentional ("I have outside thoughts when thinking"), and Nonplanning ("I plan trips well ahead of time" reverse scored) forms of impulsivity. The total score is calculated by summing the three subscale scores. Higher scores are interpreted as higher levels of impulsivity. Internal consistency for the BIS-11 total score (i.e., all 30 items) in this study is acceptable (Cronbach's $\alpha=.86$ ).

\subsubsection{Traumatic Antecedent Questionnaire}

The Traumatic Antecedent Questionnaire (TAQ) is a 42-item self-report questionnaire that assesses an individual's personal positive and negative experiences using a 4-point intensity scale (from $0=$ "never or not at all" to $3=$ "often or very much") and across four life stages (ages 0-6, 7-12, 13-18, adult (Saleptsi et al., 2004)). As we reported in other analyses of this data set (Stoltenberg et al., 2011a, 2012), we used scores on the TAQ to divide our sample into groups that had experienced relatively different exposure to childhood trauma. We used a slightly modified version of the TAQ whereby we assessed only two life stages (0-12 and 13-18). Therefore, we are unable to differentiate early and late childhood. In this study, we report scores from only the negative experience scales representing the Trauma factor [physical abuse (e.g., "I was beaten, kicked or punched by someone close to me"), sexual abuse (e.g., "Someone (older) touched me sexually, against my wishes or tried to make me touch them"), witnessing (e.g., "I witnessed physical violence in my family"), and other traumas (e.g., "I was involved in a serious accident") (Saleptsi et al., 2004)] from childhood (ages $0-12$ ). The internal consistency among these four scales is acceptable (Cronbach's $\alpha=0.79$ in this study).

\subsection{Genotyping}

DNA was extracted from buccal cells using the DNeasy Blood \& Tissue Kit (Qiagen, Inc., Valencia, California, USA). Genotype calls were made without knowledge of gender, childhood trauma status, or impulsivity scores.

TPH2 SNP (rs1386483) genotype was assayed using polymerase chain reaction (PCR) amplification and restriction digest, using PCR forward and reverse primers: 5'-GCTG GCTCTGAACGTGTATTTTG-3' and 5'-TTTGGCTGATTTTCCTAATTAAT-3' (Stoltenberg et al., 2006). The PCRs were performed in $20 \mu \mathrm{l}$ reactions containing $25 \mathrm{ng}$ of DNA, 1× GoTaq Master Mix (Promega, Madison, Wisconsin, USA), and $10 \mu \mathrm{M}$ of each primer. The 
STOLTENBERG, Christ, AND Highland,

PROGRESS IN NEURO-PSYCHOPHARMACOLOGY E BIOLOGICAL PSYCHIATRY 39 (2012)

PCR amplification conditions consisted of $7 \mathrm{~m}$ initial denaturation at $95^{\circ} \mathrm{C}$, followed by 35 cycles of $95^{\circ} \mathrm{C}$ for $45 \mathrm{~s}, 52^{\circ} \mathrm{C}$ for $45 \mathrm{~s}$, and $72^{\circ} \mathrm{C}$ for $45 \mathrm{~s}$, with a final extension of $7 \mathrm{~m}$ at $72^{\circ} \mathrm{C}$. The polymorphism was recognized by digestion with SspI (NewEngland BioLabs, Ipswich, Massachusetts, USA) for $2 \mathrm{~h}$ at $37^{\circ} \mathrm{C}$. The fragments were separated by electrophoresis on a 3\% agarose gel and visualized under ultraviolet light with ethidium bromide stain.

5-HTTLPR and rs25531 genotypes were assayed using PCR forward and reverse primers: 5'-TCCTCCGCTTTGGCGCCTCTTCC-3' and 5'-TGGGGGTTGCAGGGGAGATCCTG-3'. The PCRs were performed in $25 \mu \mathrm{l}$ reactions containing $25 \mathrm{ng}$ of DNA, 1× GoTaq Flexi buffer, $0.25 \mathrm{mM} \mathrm{MgCl}_{2}, 5 \mathrm{nM}$ dNTPs, $200 \mathrm{nM}$ of each primer, and $0.625 \mathrm{U}$ Taq polymerase (Promega, Madison, Wisconsin, USA). The PCR amplification conditions were followed as previously described (Wendland et al., 2006). The rs25531 polymorphism was recognized by digestion with HpaII with 1× BSA (New England BioLabs, Ipswich, Massachusetts, USA) for $4 \mathrm{~h}$ at $37^{\circ} \mathrm{C}$ using $7 \mu \mathrm{l}$ of the PCR product. Digest product and PCR product were separated by electrophoresis on a 3.5\% agarose gel and visualized under ultraviolet light with ethidium bromide stain.

MAOA $u$ VNTR genotype was assayed using PCR forward and reverse primers: 5'-ACA GCCTGACCGTGGAGAAG-3' and 5'-GAACGGACGCTCCATTCGGA-3' (Stoltenberg et al., 2006). The PCRs were performed in $25 \mu$ r reactions containing 25 ng of DNA, $1 \times$ GoTaq Flexi buffer, $0.25 \mathrm{mM} \mathrm{MgCl}_{2}, 5 \mathrm{nM}$ dNTPs, $10 \mu \mathrm{M}$ of each primer, and $0.625 \mathrm{U}$ Taq polymerase (Promega, Madison, Wisconsin, USA). The PCR amplification conditions consisted of $5 \mathrm{~m}$ initial denaturation at $94^{\circ} \mathrm{C}$, followed by 35 cycles of $94^{\circ} \mathrm{C}$ for $1 \mathrm{~m}, 55^{\circ} \mathrm{C}$ for $2 \mathrm{~m}$, and $72^{\circ} \mathrm{C}$ for $3 \mathrm{~m}$, with a final extension of $5 \mathrm{~m}$ at $72^{\circ} \mathrm{C}$. The fragments were separated by electrophoresis on a 3\% agarose gel and visualized under ultraviolet light with ethidium bromide stain.

HTR1A C-1019G (rs6295) genotype was assayed using PCR forward and reverse primers: 5'-CTGAGGGAGTAAGGCTGGAC-3' and 5'-GAAGAAGACCGAGTGTGTCTAC-3' (Villafuerte et al., 2009). The PCRs were performed in $10 \mu \mathrm{l}$ reactions containing $100 \mathrm{ng}$ DNA, $1 \times$ Hot Master Taq buffer with $25 \mathrm{mM} \mathrm{Mg}^{2+}, 0.25 \mathrm{mM} \mathrm{MgCl}_{2}, 10 \times \mathrm{BSA}^{2}, 2.5 \mathrm{nM}$ dNTPs, $40 \mathrm{nM}$ of each primer, and 0.5 U Hot Master Taq DNA polymerase (5 PRIME, Inc., Gaithersburg, Maryland, USA). The PCR amplification conditions consisted of $5 \mathrm{~m}$ initial denaturation at $94^{\circ} \mathrm{C}$, followed by 35 cycles of $94^{\circ} \mathrm{C}$ for $30 \mathrm{~s}, 54^{\circ} \mathrm{C}$ for $30 \mathrm{~s}$, and $72^{\circ} \mathrm{C}$ for $30 \mathrm{~s}$, with a final extension of $5 \mathrm{~m}$ at $72^{\circ} \mathrm{C}$. The polymorphism was recognized by digestion with HypCH4 IV with $1 \times$ BSA (New England BioLabs, Ipswich, MA, USA) for $2 \mathrm{~h}$ at $37^{\circ} \mathrm{C}$. The fragments were separated by electrophoresis on a $2.5 \%$ agarose gel and visualized under ultraviolet light with ethidium bromide.

HTR1B G861C (rs6296) and HTR2A T102C (rs6313) were amplified using a Taqman SNP Genotyping Assay (Applied Biosystems, Foster City, California). PCRs were performed in $20 \mu \mathrm{l}$ reactions containing $20 \mathrm{ng}$ DNA, $1 \times$ Taqman Master Mix, and 2× Taqman primers/ probes mixture. PCR amplification conditions consisted of $10 \mathrm{~m}$ initial denaturation at $95^{\circ} \mathrm{C}$, followed by 40 cycles of $95^{\circ} \mathrm{C}$ for $15 \mathrm{~s}$ and then $60^{\circ} \mathrm{C}$ for $1 \mathrm{~m}$. Reactions were run on a StepOnePlus Real-Time PCR System (Applied Biosystems, Foster City, California). End point FAM and VIC fluorescence levels were analyzed using ABI Sequence Detection Software v1.2.3 (Applied Biosystems, Foster City, California), and genotype calls were made based on the level of fluorescence signal. 
StoltenBerg, Christ, AND Highland,

PROGRESS IN NEURO-PSYCHOPHARMACOLOGY E BIOLOGICAL PSYCHIATRY 39 (2012)

All alleles were in Hardy-Weinberg equilibrium and allele frequencies were consistent with previous reports. Allele frequencies for the assayed polymorphisms are shown in Table 1.

\begin{tabular}{|c|c|c|c|}
\hline Polymorphism & Genotype (n) & Allele frequency & $\begin{array}{c}\text { Hardy-Weinberg } \\
\text { equilibrium } \chi^{2} \text { (p-value) }\end{array}$ \\
\hline ТРH2 (rs1386483) & $\begin{array}{c}\text { G/G (224) } \\
\text { G/A (164) } \\
\text { A/A (51) }\end{array}$ & $\begin{aligned} G & =0.697 \\
A & =0.303\end{aligned}$ & $5.559(0.062)$ \\
\hline HTR1A (rs6295) & $\begin{array}{c}\text { G/G (103) } \\
\text { C/G (240) } \\
\text { C/C (94) }\end{array}$ & $\begin{array}{l}G=0.510 \\
C=0.490\end{array}$ & $4.316(0.117)$ \\
\hline HTR2A (rs6313) & $\begin{array}{c}\mathrm{C} / \mathrm{C}(142) \\
\mathrm{C} / \mathrm{T}(208) \\
\mathrm{T} / \mathrm{T}(79)\end{array}$ & $\begin{array}{l}\mathrm{C}=0.573 \\
\mathrm{~T}=0.427\end{array}$ & $0.035(0.983)$ \\
\hline HTR1B (rs6296) & $\begin{array}{c}\text { G/G (240) } \\
\text { G/C (158) } \\
\text { C/C (40) }\end{array}$ & $\begin{array}{l}G=0.728 \\
C=0.272\end{array}$ & $3.215(0.200)$ \\
\hline 5-HTTLPR & $\begin{array}{c}\text { L/L (143) } \\
\text { L/S (201) } \\
\text { S/S (92) }\end{array}$ & $\begin{array}{l}L=0.558 \\
S=0.442\end{array}$ & $1.858(0.395)$ \\
\hline rs25531 & $\begin{array}{c}\text { A/A (379) } \\
\text { A/G (54) } \\
\text { G/G (3) }\end{array}$ & $\begin{array}{l}A=0.931 \\
G=0.069\end{array}$ & $0.361(0.835)$ \\
\hline 5-HTTLPR and rs25531 & $\begin{array}{c}\text { LA/LA (116) } \\
\text { LA/LG (24) } \\
\text { LG/LG (3) } \\
\text { LA/SA (172) } \\
\text { LA/SG (2) } \\
\text { LG/SA (27) } \\
\text { SA/SA (91) } \\
\text { SA/SG (1) }\end{array}$ & $\begin{aligned} \mathrm{LA} & =0.493 \\
\mathrm{LG} & =0.065 \\
\mathrm{SA} & =0.438 \\
\mathrm{SG} & =0.003\end{aligned}$ & $4.879(0.675)$ \\
\hline MAOA uVNTR (females) & $\begin{array}{c}3 / 3(32) \\
3 / 4(124) \\
3 / 5(2) \\
4 / 4(122) \\
4 / 5(4)\end{array}$ & $\begin{array}{c}3=0.335 \\
3.5=0.000 \\
4=0.655 \\
5=0.011\end{array}$ & $0.04(1.000)$ \\
\hline MAOA uVNTR (males) & $\begin{array}{c}3(53) \\
3.5(1) \\
4(97) \\
5(3)\end{array}$ & $\begin{array}{c}3=0.344 \\
3.5=0.006 \\
4=0.630 \\
5=0.019\end{array}$ & \\
\hline
\end{tabular}

Note: Only alleles that were observed in this sample are listed. 
StoltenberG, Christ, AND Highland,

PROGRESS IN NEURO-PSYCHOPHARMACOLOGY E BIOLOGICAL PSYCHIATRY 39 (2012)

\subsection{Statistical analyses}

Analyses of variance were performed using the univariate general linear model (GLM) procedure to test associations between (1) gender, (2) childhood trauma (low vs. high), (3) the TPH2 (rs1386483) genotype (G/G vs. A allele carriers), (4) the triallelic 5-HTTLPR genotype ( $\mathrm{LA}_{\mathrm{A}} / \mathrm{LA}_{\mathrm{A}}$ [i.e., higher transcriptional efficiency] vs. $\mathrm{S}$ or $\mathrm{Lg}$ allele carriers [i.e., lower transcriptional efficiency]), (5) the MAOA uVNTR genotype (high expression [3.5-repeat or 4-repeat carriers] vs. low [all others]), (6) the HTR1A (rs6295) genotype (G/G vs. C allele carriers), (7) the HTR1B (rs6296) genotype (G/G vs. C allele carriers), (8) HTR2A (rs6313) genotype (C/C vs. $\mathrm{T}$ allele carriers), and all of the two-way interactions, with age as a covariate. All genotypes were dichotomized to reduce the number of potential categories and comparisons. Groupings were determined from reports in the literature on function (i.e., 5-HTTLPR, MAOA, rs6295, rs6313) or because of relatively low minor allele frequency (i.e., rs1386483 and rs6296). Because we were concerned about the number of observations per cell, we decided to examine only main effects and two-way interactions. We first analyzed BIS-11 total score and then conducted supplemental analyses with its three subscale scores. To reduce the effects of outliers, we Winsorized scores by setting all outliers to the nearest nonoutlier score.We used an online False Discovery Rate (FDR) calculator to control the risk of false positive findings (http://sdmproject.com/utilities). All statistical analyses were conducted using IBM SPSS (version 19).

For an additional supplementary analysis we constructed an Aggregate Genetic Risk Score (AGRS), which is the sum of the five genotype values associated with higher impulsivity in our initial analysis (i.e., TPH2 [A/_ $=1, \mathrm{G} / \mathrm{G}=0]$, MAOA $[\mathrm{H}=1, \mathrm{~L}=0], 5-\mathrm{HTTLPR}$ $\left[\mathrm{L}_{\mathrm{A}} / \mathrm{LA}_{\mathrm{A}}=1, \mathrm{~S}\right.$ or $\mathrm{LG}_{\mathrm{G}}$ carrier $\left.=0\right], \mathrm{HTR} 2 \mathrm{~A}\left[\mathrm{C} / \mathrm{C}=1, \mathrm{~T} /{ }_{-}=0\right]$ and HTR1B $\left[\mathrm{C} /{ }_{-}=1, \mathrm{G} / \mathrm{G}=0\right]$ ). Because HTR1A (rs6295) genotype was not found to be associated with impulsivity in this study, we did not include it in the calculation of the AGRS. Values for the AGRS ranged from 0 to 5 .

\section{Results}

The overall mean of the Winsorized BIS-11 total score was $64.90(\mathrm{SD}=11.04)$. The mean (SD) for the Winsorized BIS-11 subscale scores was Attentional 17.58 (4.12), Nonplanning 24.31 (4.98), and Motor 23.00 (4.49). Because the score distribution on our quantitative childhood trauma measure was not normal (mean $=0.96, \mathrm{SD}=1.35$, skewness $=2.98$, kurtosis $=12.29$ ) we constructed a two-level variable representing levels of trauma by summing the scores for four subscales and then using a score of 2 as a cut point for the low (n $=360)$ and high $(n=63)$ groups. Men $(14.97 \%)$ and women $(14.86 \%)$ were equally represented in the high trauma group $\left(\chi^{2}=0.001,1 \mathrm{df}, \mathrm{p}=.976\right)$.

In a univariate GLM with BIS-11 total score as the dependent variable, there was a significant main effect for the experience of childhood trauma (partial $\eta^{2}=0.020$, power $=$ 0.793; see Table 2). Thosewho had experienced higher levels of childhood trauma ( $\mathrm{M}=$ $70.81, \mathrm{SE}=2.42$ ) had higher mean scores than those who had experienced lower levels of childhood trauma $(\mathrm{M}=63.79, \mathrm{SE}=1.07)$. No other main effects were significant (i.e., $\mathrm{p}<.05$ and FDR $<.10$ ). There were significant interaction effects between gender and TPH2 (rs1386483) genotype $\left(\eta^{2}=0.018\right.$, power $=0.743$; see Fig. $\left.1 \mathrm{a}\right)$; and between gender and 
STOLTENBERG, Christ, AND Highland,

PROGRESS IN NEURO-PSYCHOPHARMACOLOGY E BIOLOGICAL PSYCHIATRY 39 (2012)

HTR2A (rs6313) genotype $\left(\eta^{2}=0.019\right.$, power $=0.772$; see Fig. $\left.1 b\right)$. There was also a significant interaction effect for the 5-HTTLPR triallelic genotype $\times$ MAOA genotype condition (partial $\eta^{2}=0.021$, power $=0.811$; see Fig. 2a). There was a significant interaction effect for the 5-HTTLPR triallelic genotype $\times$ HTR2A (rs6313) genotype condition (partial $\eta^{2}=0.029$, power $=0.919$; see Fig. $2 \mathrm{~b}$ ). Finally, there was a significant interaction effect for the HTR2A (rs6313) genotype $\times$ HTR1B (rs6296) genotype condition $\left(\right.$ partial $\eta^{2}=0.018$, power $=0.748$, see Fig. 2c). Thus, while we observed no main effects for particular genotypes, we did observe evidence of genetic effects that depended on context (i.e., gender and other genotypes).

Table 2. F and p-values from general linear models for Barratt Impulsiveness Scale (version 11) total scores and its three subscales

\begin{tabular}{|c|c|c|c|c|c|c|c|c|}
\hline \multirow[t]{2}{*}{ Source } & \multicolumn{2}{|c|}{ Total } & \multicolumn{2}{|c|}{ Attentional } & \multicolumn{2}{|c|}{ Nonplanning } & \multicolumn{2}{|c|}{ Motor } \\
\hline & $\mathrm{F}$ & $\mathrm{p}^{*}$ & $\mathrm{~F}$ & $\mathrm{p}$ & $\mathrm{F}$ & $\mathrm{p}$ & $\mathrm{F}$ & $\mathrm{p}$ \\
\hline 1. Age & 0.441 & .507 & 4.738 & .030 & 0.448 & .504 & 0.110 & .740 \\
\hline 2. Gender & 4.182 & .042 & 1.740 & .188 & 1.886 & .171 & 4.779 & .029 \\
\hline 3. Trauma & 7.756 & .006 & 5.708 & .017 & 0.206 & .650 & 16.186 & .000 \\
\hline 4. TPH2 & 0.655 & .419 & 0.000 & .988 & 0.465 & .496 & 1.470 & .226 \\
\hline 5. HTT & 0.441 & .507 & 0.901 & .343 & 0.197 & .658 & 1.506 & .221 \\
\hline 6. MAOA & 4.533 & .034 & 3.984 & .047 & 4.852 & .028 & 0.668 & .414 \\
\hline 7. HTR1A & 0.210 & .647 & 0.164 & .686 & 0.451 & .502 & 0.540 & .463 \\
\hline 8. HTR1B & 1.655 & .199 & 0.085 & .770 & 4.131 & .043 & 0.311 & .578 \\
\hline 9. HTR2A & 0.596 & .441 & 0.209 & .648 & 0.004 & .947 & 2.328 & .128 \\
\hline $2 \times 3$ & 0.050 & .824 & 0.824 & .365 & 0.167 & .683 & 0.024 & .878 \\
\hline $2 \times 4$ & 6.863 & .009 & 6.301 & .012 & 0.969 & .326 & 8.454 & .004 \\
\hline $2 \times 5$ & 0.233 & .630 & 0.607 & .436 & 0.154 & .695 & 0.000 & 1.000 \\
\hline $2 \times 6$ & 0.600 & .439 & 0.017 & .897 & 0.920 & .338 & 0.850 & .357 \\
\hline $2 \times 7$ & 2.023 & .156 & 0.577 & .448 & 0.759 & .384 & 3.108 & .079 \\
\hline $2 \times 8$ & 3.370 & .067 & 3.680 & .056 & 2.963 & .086 & 0.519 & .472 \\
\hline $2 \times 9$ & 7.355 & .007 & 3.715 & .055 & 5.622 & .018 & 4.449 & .036 \\
\hline $3 \times 4$ & 0.676 & .412 & 0.808 & .369 & 0.131 & .718 & 0.560 & .455 \\
\hline $3 \times 5$ & 2.255 & .134 & 0.680 & .410 & 0.015 & .903 & 7.527 & .006 \\
\hline $3 \times 6$ & 2.264 & .133 & 0.008 & .930 & 5.870 & .016 & 0.701 & .403 \\
\hline $3 \times 7$ & 2.426 & .120 & 1.649 & .200 & 0.737 & .391 & 2.607 & .107 \\
\hline $3 \times 8$ & 0.178 & .673 & 0.932 & .335 & 0.335 & .563 & 0.284 & .595 \\
\hline $3 \times 9$ & 0.255 & .614 & 0.194 & .660 & 0.002 & .968 & 0.744 & .389 \\
\hline $4 \times 5$ & 1.224 & .269 & 0.070 & .791 & 0.033 & .855 & 7.029 & .008 \\
\hline $4 \times 6$ & 0.015 & .902 & 0.020 & .888 & 0.163 & .686 & 0.001 & .981 \\
\hline $4 \times 7$ & 0.382 & .537 & 0.039 & .843 & 1.180 & .278 & 0.213 & .645 \\
\hline $4 \times 8$ & 0.134 & .714 & 0.055 & .814 & 0.151 & .698 & 0.452 & .502 \\
\hline $4 \times 9$ & 2.243 & .135 & 1.071 & .301 & 2.427 & .120 & 0.830 & .363 \\
\hline $5 \times 6$ & 8.123 & .005 & 2.037 & .154 & 11.801 & .001 & 2.925 & .088 \\
\hline $5 \times 7$ & 0.634 & .427 & 0.106 & .744 & 0.322 & .571 & 2.566 & .110 \\
\hline $5 \times 8$ & 0.008 & .931 & 0.005 & .945 & 0.070 & .791 & 0.024 & .878 \\
\hline
\end{tabular}


STOLTENBERG, CHRist, AND Highland,

PROGRESS IN NEURO-PSYCHOPHARMACOLOGY E BIOLOGICAL PSYCHIATRY 39 (2012)

\begin{tabular}{|c|c|c|c|c|c|c|c|c|}
\hline \multirow[t]{2}{*}{ Source } & \multicolumn{2}{|c|}{ Total } & \multicolumn{2}{|c|}{ Attentional } & \multicolumn{2}{|c|}{ Nonplanning } & \multicolumn{2}{|c|}{ Motor } \\
\hline & $\mathrm{F}$ & $\mathrm{p}^{*}$ & $\mathrm{~F}$ & $\mathrm{p}$ & $\mathrm{F}$ & $\mathrm{p}$ & $\mathrm{F}$ & $\mathrm{p}$ \\
\hline $5 \times 9$ & 11.316 & .001 & 8.403 & .004 & 7.158 & .008 & 5.956 & .015 \\
\hline $6 \times 7$ & 0.919 & .338 & 0.026 & .872 & 2.710 & .101 & 0.386 & .535 \\
\hline $6 \times 8$ & 0.000 & .994 & 0.281 & .596 & 0.408 & .523 & 0.059 & .809 \\
\hline $6 \times 9$ & 0.284 & .594 & 0.000 & .982 & 0.424 & .516 & 0.292 & .589 \\
\hline $7 \times 8$ & 0.193 & .660 & 3.011 & .083 & 0.007 & .934 & 0.215 & .643 \\
\hline $7 \times 9$ & 0.823 & .365 & 2.015 & .157 & 0.731 & .393 & 0.008 & .928 \\
\hline $8 \times 9$ & 6.945 & .009 & 2.242 & .135 & 11.780 & .001 & 1.267 & .261 \\
\hline Adj. $R^{2}$ & 0.139 & & 0.080 & & 0.086 & & 0.122 & \\
\hline
\end{tabular}

Note: $\mathrm{TPH} 2$ = rs1386483 genotype; HTT = 5-HTTLPR + rs25531 genotype; MAOA = MAOA uVNTR genotype; HTR1A = rs6295 genotype; HTR1B = rs6296 genotype; HTR2A = rs6313 genotype. For all, $\mathrm{df}=1,422$. Stage 1 of the analysis included only BIS-11 total score as a dependent variable. Stage 2 of the analysis included the BIS-11 factor subscales (Attentional, Nonplanning, Motor) as dependent variables. ${ }^{*} \mathrm{p}<.05$ and FDR $<.10$ are shown in bold.
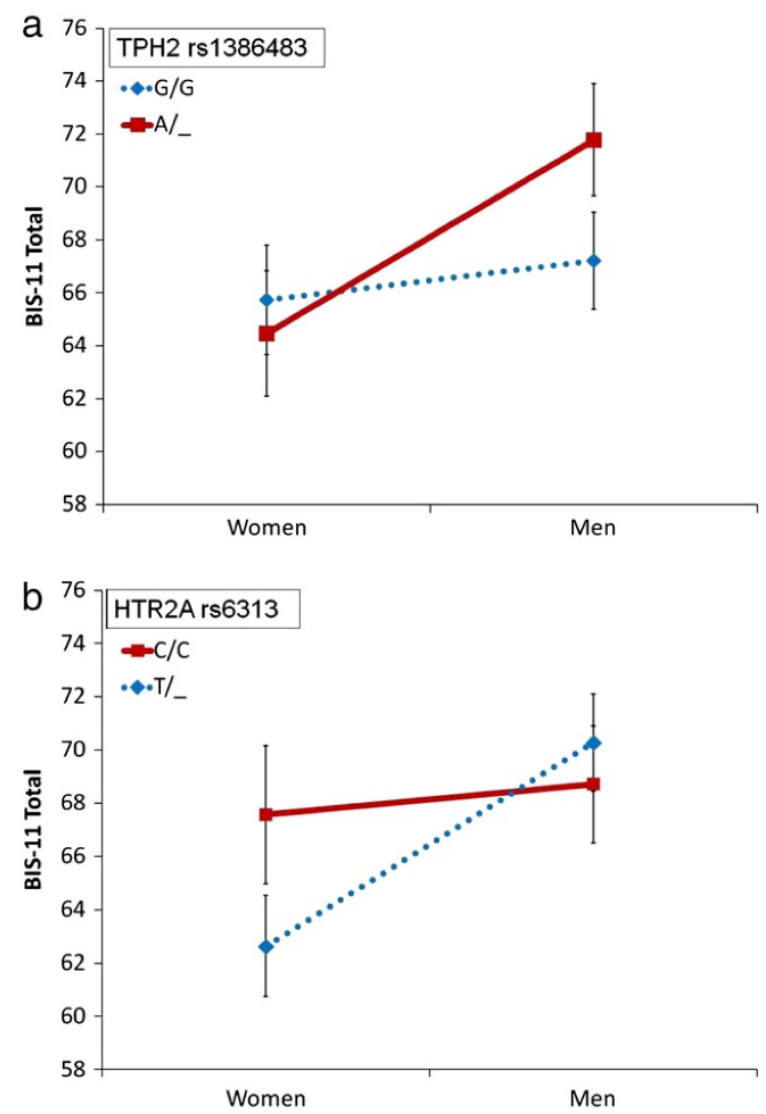

Figure 1. Mean BIS-11 total scores for groups defined by (a) gender $\times$ TPH2 (rs1386483) genotype; (b) gender $\times$ HTR2A (rs6313) genotype. Error bars represent standard errors of the mean. 
STOLTENBERG, CHRist, AND Highland,
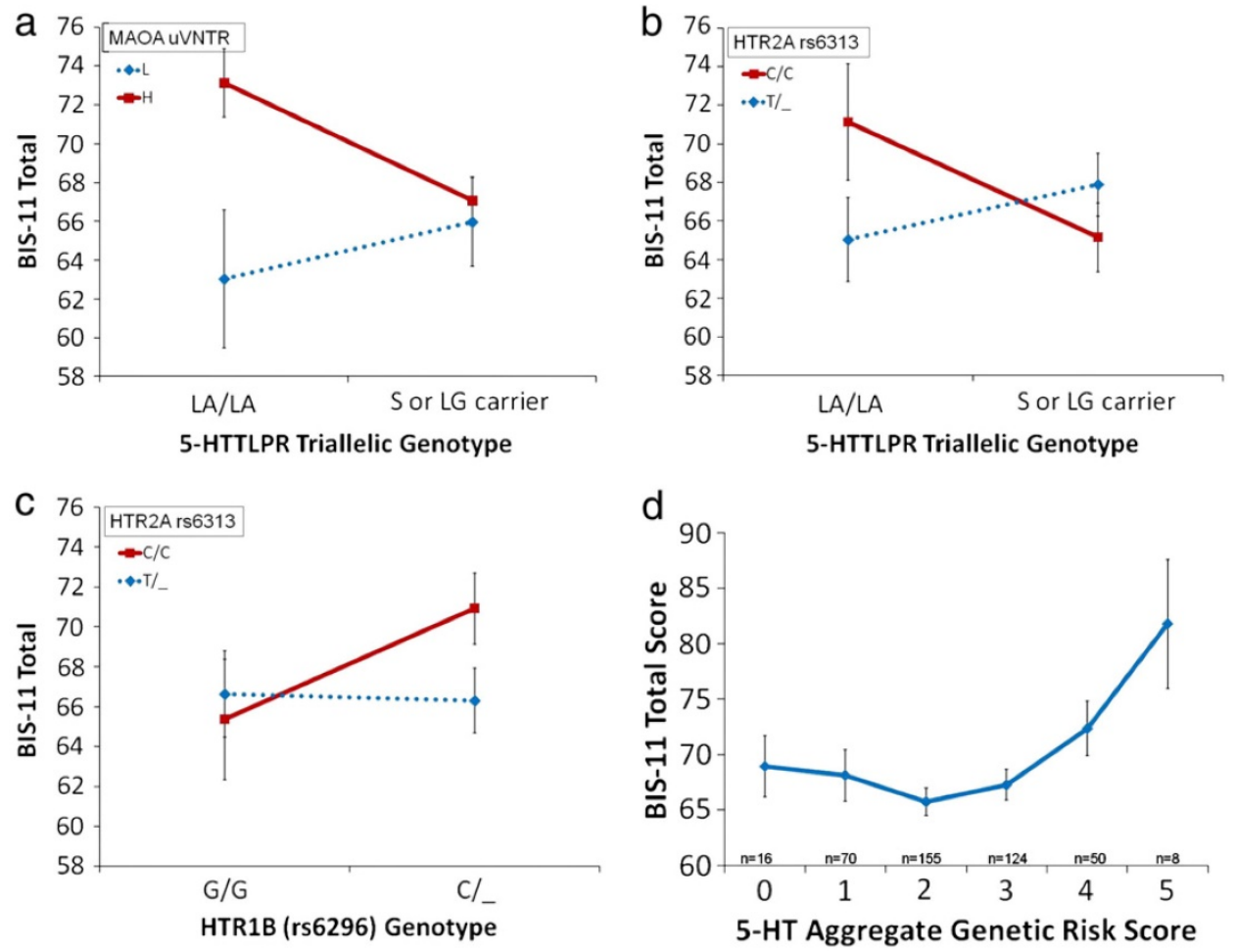

Figure 2. Mean BIS-11 total scores for groups defined by (a) 5-HTTLPR triallelic genotype $\times$ MAOA (uVNTR) genotype; (b) 5-HTTLPR triallelic genotype $\times$ HTR2A (rs6313) genotype; (c) HTR1B (rs6296) genotype $\times$ HTR2A (rs6313) genotype; (d) Aggregate Genetic Risk Score. Error bars represent standard errors of the mean.

To examine the combined effects of the five polymorphisms (rs1386483, 5-HTTLPR triallelic, MAOA uVNTR, rs6296, and rs6313) that were identified as being associated with BIS11 total score in a context dependent manner, we constructed an Aggregate Genetic Risk Score. To determine if the AGRS explained a significant amount of variation in BIS-11 total score, we ran a GLM with Gender, childhood trauma, and AGRS as independent variables with a model that included main effects and two-way interactions. The main effects for childhood trauma $\left(\mathrm{F}(1,407)=4.368, \mathrm{p}=.037, \eta^{2}=.011\right.$, power $\left.=.550\right)$ and AGRS $(\mathrm{F}(5,407)=$ $2.440, \mathrm{p}=.034, \eta^{2}=.029$, power $=.770$; see Fig. $2 \mathrm{~d}$ ) were significantly associated with BIS11 total score. None of the two-way interactions were statistically significant. The model explained $6.6 \%$ of the variance in BIS- 11 total score. We estimated curves for AGRS and found only the quadratic curve fit $\left(\mathrm{F}(2,424)=5.355, \mathrm{p}=.005, \mathrm{R}^{2}=.025\right)$. The quadratic curve fit and the linear curve did not suggest that the effects of these genotypes are not strictly additive but that certain genotype combinations are associated with higher impulsivity scores than others. 
StoltenberG, Christ, AND Highland,

To determine if the pattern of effects observed in the BIS-11 total score was reflected in the subscale scores, we used the same regression model of main effects and two-way interactions. For the Attentional subscale, none of the main effects or interaction effects had $\mathrm{p}<.05$ and FDR $<.10$ (see Table 2).

For the Nonplanning subscale there were no main significant main effects (i.e., $\mathrm{p}<.05$ and FDR $<.10$ ). There were, however, three significant epistatic interaction effects. The patterns of these effects were in the same direction as those seen in the BIS- 11 total scores. There was a significant interaction effect for the 5-HTTLPR triallelic genotype $\times$ MAOA genotype condition $\left(\mathrm{F}(1,385)=11.801, \mathrm{p}=.001\right.$, partial $\eta^{2}=0.030$, power $\left.=0.929\right)$. There was also a significant interaction effect for the 5-HTTLPR triallelic genotype $\times$ HTR2A (rs6313) genotype condition $\left(\mathrm{F}(1,385)=7.158, \mathrm{p}=.008\right.$, partial $\eta^{2}=0.018$, power $\left.=0.761\right)$. Finally, there was a significant interaction effect for the HTR2A (rs6313) genotype $\times$ HTR1B (rs6296) genotype condition $\left(\mathrm{F}(1,385)=11.780, \mathrm{p}=.001\right.$, partial $\eta^{2}=0.030$, power $\left.=0.928\right)$. Epistatic interactions involving 5-HTTLPR, HTR2A, and HTR1B were observed for Nonplanning impulsivity scores. These effects appear to be those that contributed to the effects observed in the BIS-11 total score and are not observed in other subscales, although nonsignificant trends are seen for 5-HTTLPR $\times$ HTR2A in both the Attentional and Motor subscales.

For the Motor subscale there was a significant (i.e., $\mathrm{p}<.05$ and FDR $<.10$ ) main effect for the experience of trauma $\left(F(1,385)=16.186, p=.000\right.$, partial $\eta^{2}=0.040$, power $\left.=0.980\right)$ that followed the pattern observed in BIS-11 total scores. In addition, there were three significant interaction effects. For the first, the pattern of the effects was in the same direction as seen in the BIS-11 total scores. Namely, there was a significant interaction effect for the gender $\times$ TPH2 $(r s 1386483)$ genotype condition $\left(F(1,385)=8.454, p=.004\right.$, partial $\eta^{2}=0.021$, power $=0.826$ ). In addition, there were two interaction effects that were unique to Motor subscale scores. There was a significant effect for the trauma $\times 5$-HTTLPR triallelic genotype condition $\left(F(1,385)=7.527, p=.006\right.$, partial $\eta^{2}=0.019$, power $=0.781$; see Fig. 3a). Finally, there was a significant interaction effect for the 5-HTTLPR genotype $\times$ TPH2 (rs1386483) genotype condition $\left(\mathrm{F}(1,385)=7.029, \mathrm{p}=.008\right.$, partial $\eta^{2}=0.018$, power $=0.753$; see Fig. $3 b$ ). The Motor impulsivity subscale scores show main effects of early life trauma and an interaction effect for gender by TPH2 genotype that was reflected in the BIS-11 total score. There were also interaction effects observed for trauma by 5-HTTLPR genotype and for 5-HTTLPR by TPH2 genotype that were unique to the Motor subscale. 
StoltenberG, Christ, and Highland,
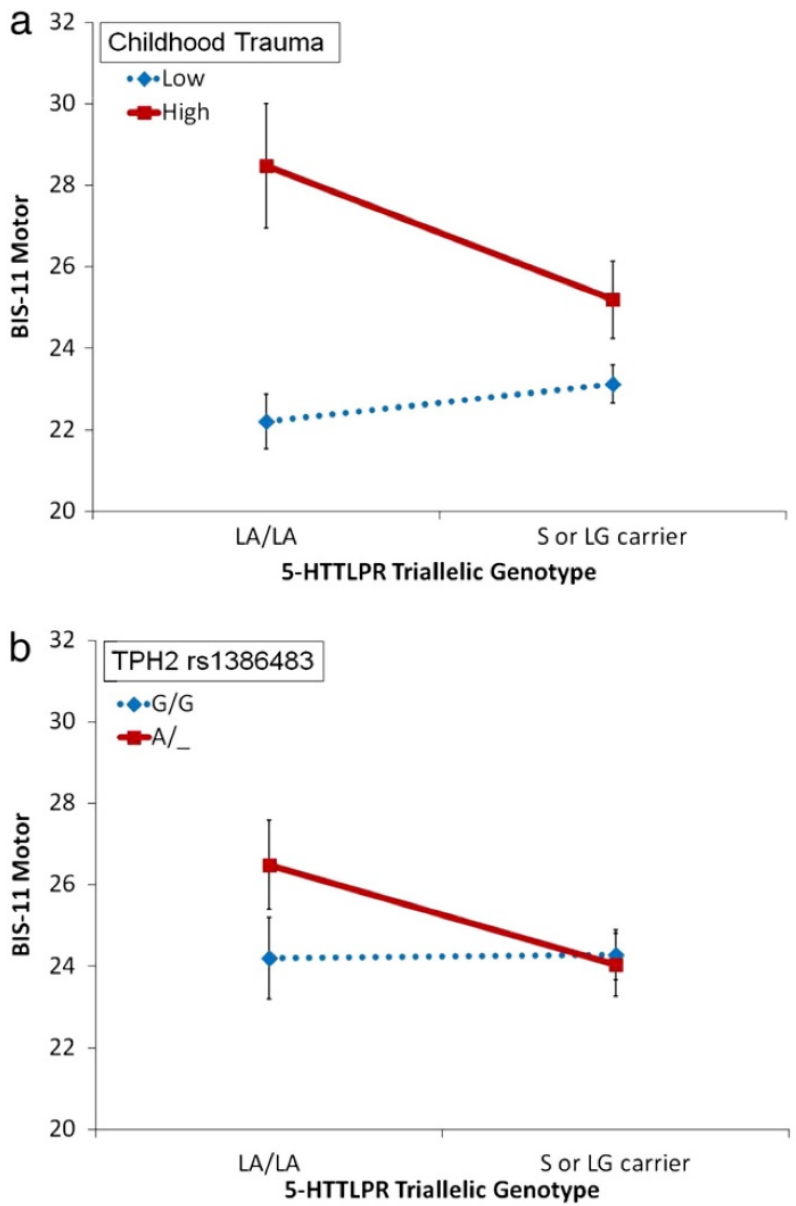

Figure 3. Mean BIS-11 Motor scores for groups defined by (a) 5-HTTLPR triallelic genotype $\times$ experience of childhood trauma; (b) 5-HTTLPR triallelic genotype $\times$ TPH2 (rs1386483) genotype. Error bars represent standard errors of the mean.

\section{Discussion}

Our primary objective in this study was to investigate potential associations between 5-HT system candidate gene polymorphisms and a well-validated measure of impulsivity. The main finding of this study is that, in specific contexts, certain genetic variants of 5-HT system components are associated with impulsivity. Our findings are consistent with the interpretation that impulsivity is a classic quantitative trait with a complex genetic architecture because the observed associations with certain genotypes and impulsivity were seen only in one gender, or only in those who experienced childhood trauma, or only in those with certain genotypes. Such context dependency, when considered against the backdrop of the large number of genetic variants in candidate genes of interest; the variety of measures that have been used to assess impulsivity in the literature; and the various populations that have been studied brings the complexity of heredity-impulsivity relations 
STOLTENBERG, CHRist, AND Highland,

into sharp relief. Our findings are also generally consistent with the hypothesis that impulsivity is associated with genotypes known or thought to either reduce synaptic 5-HT availability or reduce post-synaptic 5-HT activation.

Often only main effects are considered in candidate gene association studies, although gender, $\mathrm{G} \times \mathrm{E}$, and epistatic interactions are increasingly being investigated. Our primary analysis utilized a general linear model with nine main effect terms and 28 two-way interaction terms that explained $13.9 \%$ of the variance in BIS-11 total score. We did not observe any main effects that survived correction for multiple comparisons on BIS-11 Total or subscale scores for age, gender, or for the following genotypes: TPH2 (rs1386483), 5-HTTLPR, MAOA (uVNTR), HTR1A (rs6295), HTR1B (rs6296), and HTR2A (rs6313). The only significant main effect was that those who had experienced higher levels of early life trauma had higher mean impulsivity scores. This trauma effect was also seen in our supplementary analyses of the Motor subscale and there was a nonsignificant trend in the same direction for the Attentional subscale. This pattern of results is consistent with the convergent evidence that adverse childhood experiences are associated with increased risk for adult psychopathology that is likely mediated by neurobiological changes and may be moderated by genotype (McCrory et al., 2011).

Out of the five statistically significant interaction effects that we report in our preliminary analysis on BIS-11 total score, three involve the HTR2A (rs6313, also known as T102C) receptor polymorphism. In each case (women, 5-HTTLPR LA/LA and HTR1B [rs6296] C allele carriers), the mean impulsivity score was higher for $\mathrm{C}$ homozygotes than for $\mathrm{T}$ allele carriers. These results strengthen the case that HTR2A genetic variation is associated with impulsivity (Bjork et al., 2002; Jakubczyk et al., 2012); and the fact that we did not observe a significant main effect for HTR2A highlights its context dependent associations with complex traits (Saiz et al., 2010; Viikki et al., 2011). Preclinical pharmacological studies with rodents show that 5-HTR2A receptor antagonists reduce premature responding in the fivechoice serial reaction time task (Winstanley, 2011). Such convergent evidence strongly implicates the 5-HTR2A receptor in behavioral control traits and should provide some measure of confidence in the use of self-report questionnaires to study the genetic architecture of impulsivity. Our finding that rs6313 genotype interacts with gender, 5-HTTLPR, and HTR1B (rs6296) genotype reflects the multifaceted nature of the 5-HT system and contrasts approaches that study human participants and those that study rodents as research subjects, which are usually not designed to test gender differences or the effects of varying genetic background.

In addition, there is growing evidence that genetic polymorphisms of the 5-HT transporter and HTR2A jointly influence outcomes that have relevance to impulsivity. In a sample of healthy Spanish Caucasians, 5-HTTLPR and HTR2A (rs6311) a significant interaction effect on the personality trait of Novelty Seeking was observed (Saiz et al., 2010). Significant interaction effects between 5-HTTLPR and rs6311 were also observed for alcohol dependence (Saiz et al., 2009) and between 5-HTTLPR and rs6313 for age of onset of bipolar disorder (Manchia et al., 2010). The combination of 5-HTTLPR LA/LA and rs6313 C/C genotypes is hypothesized to be associated with reduced synaptic 5-HT availability and reduced 5-HTR2A receptor densities. Such a combination would likely result in relatively low 
STOLTENBERG, CHRist, AND Highland,

levels of 5-HT neurotransmission. We were unable to find reports of epistatic interaction between HTR2A and HTR1B polymorphisms.

Carver et al. (2011) found that for impulsivity in response to emotions 5-HTTLPR genotype interacted with childhood adversity. The pattern of this interaction was that the LG or S (i.e., low transcriptional efficiency) alleles were associated with higher levels of impulsivity for those that experienced higher levels of childhood adversity. This contrasts with our finding that the experience of higher levels of childhood trauma was associated with higher Motor impulsivity for both LA homozygotes and for LG or S carriers, most dramatically in the LA homozygotes. In other words, the 5-HTLPR effect (i.e., LA homozygotes more impulsive) was mainly observed in the high childhood trauma condition. It should be noted, however, that the items that make up the BIS-11 Motor scale are not emotionrelated. It seems that the associations reported by Carver et al. (2011) are with a different type of impulsivity that is independent of those assessed by the BIS-11. These two studies used different measures of impulsivity and childhood trauma/adversity, so it is difficult to directly compare the results. We examined several additional genetic polymorphisms, and our sample size was $40 \%$ larger than that of Carver et al. (2011); but because our study did not assess emotion-related impulsivity, our finding should not be considered a nonreplication. Rather, both demonstrate the context-dependent effects of 5-HTTLPR on facets of impulsivity and suggest that much more work is needed to fully understand the genetic and contextual influences underlying impulsivity. Our findings are consistent with a report that found that among patients with borderline personality disorder who had experienced higher numbers of serious life events those with the L/L 5-HTTLPR genotype had higher impulsivity than those who carried an S allele (Wagner et al., 2009). In that study, a German version of the Barratt Impulsiveness Scalewas used to assess impulsivity and comparison groups were formed based on the severity of serious life events. Therefore the design of the Wagner et al. (2009) study was similar to ours, although our study population was more similar to that of the Carver et al.'s (2011) study. Clearly, impulsivity is a complex construct and different measures are assessing different impulsivity facets.

We report two significant gender $\times$ genotype interactions involving HTR2A (rs6313) and TPH2 (rs1386483), respectively. We found that in women, but not in men, those with the $\mathrm{C} / \mathrm{C}$ rs6313 genotype had significantly higher mean BIS-11 total scores than those carrying a T allele. Recently a study found that the $\mathrm{C} / \mathrm{C}$ genotype of rs6313was associated with higher suicide risk in women, but not in men (Wrzosek et al., 2011). This supports the notion that forwomen, the C/C genotype of rs6313 is associated with impulsive acts. Because 5-HT synthesis is lower for women than men (Nishizawa et al., 1997), the relatively lower density of 5-HTR2A receptors for those homozygous for the rs6313 C allele might be associated with significantly lower 5-HT neurotransmission. Another recent study reported that the effects of polymorphisms in HTR2A (rs7997012 and rs6311) on response to selective serotonin reuptake inhibitor treatment for major depression were moderated by gender (Viikki et al., 2011). Although we examined a different polymorphism and a different outcome, our results also provide some evidence that the influence of genetic variation in the 5-HT system on important behavioral outcomes is moderated by gender. We also found that in men, but not in women, TPH2 (rs1386483) A allele carriers had significantly higher mean 
STOLTENBERG, CHRist, AND Highland,

BIS-11 total scores. This result is consistent with our earlier work using behavioral inhibition as a measure of impulsivity (Stoltenberg et al., 2006). Men and women differ in measures of 5-HT synthesis (Nishizawa et al., 1997) and brain 5-HT receptor density (Biver et al., 1996; Soloff et al., 2010), as well as in the relations between 5-HT system genes and peripheral indices of 5-HT function (Williams et al., 2003) and response to psychological stressors (Jabbi et al., 2007). Genotype $\times$ gender interactions on psychological traits of interest or aspects of psychiatric illness should be expected and explicitly investigated. Such gender specific effects might partially mediate gender differences in prevalence of behavioral disorders impacted by 5-HT system function and might influence impulsivity by affecting 5-HT mediated drive to withdraw (Tops et al., 2009).

We report a significant epistatic interaction between HTR2A (rs6313) and HTR1B (rs6296) genotypes on BIS-11 total score that was also observed in the Attentional subscale. To our knowledge, this is the first report of epistatic interaction between polymorphisms in these two genes. A recent report indicated that in the brains of rats exposed to chronic buspirone treatment, the density of 5-HTR 1 в decreased whereas the density of 5-HTR 2 A receptors increased (Sato et al., 2010). Such a finding indicates a functional relation between 5-HTR 1 B and $5-\mathrm{HTR}_{2 \mathrm{~A}}$ receptors, which supports the plausibility of epistatic interaction between HTR1B and HTR2A.

Recently there has been increasing interest in the use of Aggregate Genetic Risk Scores (AGRS) in association studies of complex traits (Shiffman et al., 2006). Such genetic risk scores are consistent with the classic notion of genetic influence on a polygenic trait such that each polymorphism contributes a small but significant amount to variation in the trait; and the scores represent the potential summative effects of the "risk" alleles. Recent studies on body mass index (Peterson et al., 2011) and the personality trait of sensation seeking (Derringer et al., 2010) have successfully utilized this approach. Our findings in the present study also support the AGRS approach in that there was a significant association between the AGRS and impulsivity. The context dependence of the genetic effects that we report, however, complicates the construction of such a score. If a given allele is a "risk" allele only in the context of another genotype, environmental exposure or gender, how should it contribute to the AGRS? In our study, we included in the AGRS only those genotypes that were found to be at least nominally associated with impulsivity in the main analyses. We assigned a score of 1 to a given genotype if it was associated with higher impulsivity in any context, and we assigned the score of 0 to the alternative genotype (i.e., risk genotypes = 5-HTTLPR La/LA, MAOA uVNTR H/_ TPH2 rs1386483 A/_HTR1B rs6296 C/_ and rs6313 C/C). It seems that the quadratic line that represents the association between our observed AGRS and impulsivity indicates the context dependence of the effects through its nonlinearity. In other words, if the genetic effects represented in the AGRS were strictly additive in nature, a linear effect would have been observed. Rather, the curvilinear effect that we observed suggests that the genetic effects are not strictly additive; but that certain combinations of genotypes are associated with higher levels of impulsivity than would be expected with an additive model. Additional work is needed to address the issue of context dependence in the construction of AGRS. 
STOLTENBERG, CHRist, AND Highland,

For $\mathrm{G} \times \mathrm{E}$ interaction studies focused on adverse early life events, more precise measures of childhood trauma should be investigated to better understand the type, timing, perpetrator, and amount of trauma that increases impulsivity later in life (Nugent et al., 2011). A recent measure called the Computerized Assisted Maltreatment Inventory (DiLillo et al., 2010) appears to be especially promising in delineating the source and influence of childhood maltreatment. We are currently developing plans for a study to utilize this valid and reliable assessment.

The present study does have some limitations that should be considered when interpreting the findings. We did not evaluate participants for psychiatric disorders. Our sample was drawn from a population of college students and therefore our results might not be generalizable to clinical populations. The sample size is modest according to current standards for candidate gene association studies. With that in mind, we carefully limited the number of statistical comparisons that we made. In our general linear models, we examined only main effects and two-way interactions. Even with that relatively conservative approach, the model resulted in a total of 37 statistical tests for the primary analysis, resulting in a strict Bonferroni adjusted significance criterion of $.05 / 37=.00135$. We chose to present FDR, which is somewhat less conservative, but is a well-accepted correction to reduce false positives (Benjamini and Hochberg, 1995). In addition, although we collected data of other measures of impulsivity including measures of behavioral inhibition, time perception and boredom susceptibility, we did not have the statistical power to test them in the face of the rising number of comparisons. In addition, because such diverse measures of impulsivity are assessing different constructs such analyses would be beyond the scope of this report. For this study, we did not conduct other statistical analyses than those reported here. Subsequent follow-up analyses may be reported elsewhere. Our sample was relatively ethnically homogeneous, which reduces the likelihood of false positive findings due to population stratification. It is unclear whether the pattern of results that we see in this sample of Caucasians will generalize to populations of different race/ethnicity; however, there is no obvious reason to a priori expect different patterns of results (Ioannidis et al., 2004).We only assayed single polymorphisms in these critical candidate genes. Clearly there are other polymorphisms in these genes that affect their function and may play a role in impulsivity, but we chose a targeted subset of available polymorphisms to investigate. Our findings should not be considered the final word on the extent or nature of influence that genetic variation has on impulsivity.

This study, when considered along with others, adds to growing evidence that genetic variation in the 5-HT system influences impulsivity in a context dependent manner. A more complete understanding of the genetic architecture of impulsivity could lead to genetically informed efforts at prevention and treatment of adverse conditions or psychiatric disorders associated with impulsivity. It is imperative that future research into the genetic architecture of impulsivity pays special attention to polymorphisms in 5-HT system genes, gender, early life trauma, and epistasis. It may be that failures to replicate genetic associations with complex psychological traits like impulsivity may be due, at least in part, to the context dependency of the effects. 
STOLTENBERG, CHRist, AND Highland,

\section{Conclusions}

Impulsivity appears to be a classic quantitative trait that is influenced by many factors, including 5-HT system genes, gender, and early life trauma. At least some of these factors appear to moderate the effects of others (i.e., epistasis, $\mathrm{G} \times \mathrm{E}$, and gender specificity) in ways that are just beginning to be understood. Our study should help to increase interest in the investigation of epistatic interactions on psychological constructs of interest such as impulsivity. As with all empirical results, the findings of this study should be considered in light of its limitations.

Acknowledgments - The authors would like to thank Parthasarathi Nag, Cynthia Anderson, Cheryl Anagnopoulos, and Melissa Lehmann who were instrumental in the collection of the study data. This work was partially supported by grants from the National Institutes of Health MH077654 and RR016479 and by a Faculty Seed Grant from the University of Nebraska Research Council. The authors have no conflicts of interest to declare.

\section{References}

Barratt ES, Felthous AR. Impulsive versus premeditated aggression: implications for mens rea decisions. Behav Sci Law 2003;21:619-30.

Barry D, Clarke M, Petry NM. Obesity and its relationship to addictions: is overeating a form of addictive behavior? Am J Addict 2009;18:439-51.

Benjamini Y, Hochberg Y. Controlling the False Discovery Rate: a practical and powerful approach to multiple testing. J R Stat Soc Ser B 1995;57:289-300.

Benko A, Lazary J, Molnar E, Gonda X, Tothfalusi L, Pap D, et al. Significant association between the C(-1019)G functional polymorphism of the HTR1A gene and impulsivity. Am J Med Genet B Neuropsychiatr Genet 2010;153B:592-9.

Beste C, Domschke K, Falkenstein M, Konrad C. Differential modulations of response control processes by 5-HT1A gene variation. Neuroimage 2010;50:764-71.

Beste C, Domschke K, Radenz B, Falkenstein M, Konrad C. The functional 5-HT1A receptor polymorphism affects response inhibition processes in a context-dependent manner. Neuropsychologia 2011;49:2664-72.

Bezdjian S, Baker LA, Tuvblad C. Genetic and environmental influences on impulsivity: a meta-analysis of twin, family and adoption studies. Clin Psychol Rev 2011;31: 1209-23.

Biver F, Lotstra F, Monclus M, Wikler D, Damhaut P, Mendlewicz J, et al. Sex difference in 5HT2 receptor in the living human brain. Neurosci Lett 1996;204:25-8.

Bjork JM, Moeller FG, Dougherty DM, Swann AC, Machado MA, Hanis CL. Serotonin 2a receptor T102C polymorphism and impaired impulse control. Am J Med Genet 2002;114:336-9.

Blonigen DM, Timko C, Moos BS, Moos RH. Impulsivity is an independent predictor of 15-year mortality risk among individuals seeking help for alcohol-related problems. Alcohol Clin Exp Res 2011;35:2082-92.

Carver CS, Johnson SL, Joormann J. Serotonergic function, two-mode models of self-regulation, and vulnerability to depression: what depression has in common with impulsive aggression. Psychol Bull 2008;134:912-43. 
STOLTENBERG, CHRist, AND Highland,

Carver CS, Johnson SL, Joormann J, Kim Y, Nam JY. Serotonin transporter polymorphism interacts with childhood adversity to predict aspects of impulsivity. Psychol Sci 2011;22:589-95.

Caspi A, Hariri AR, Holmes A, Uher R, Moffitt TE. Genetic sensitivity to the environment: the case of the serotonin transporter gene and its implications for studying complex diseases and traits. Am J Psychiatry 2010;167:509-27.

Conner TS, Jensen KP, Tennen H, Furneaux HM, Kranzler HR, Covault J. Functional polymorphisms in the serotonin 1B receptor gene (HTR1B) predict self-reported anger and hostility among young men. Am J Med Genet B Neuropsychiatr Genet 2010;153B:67-78.

Derringer J, Krueger RF, Dick DM, Saccone S, Grucza RA, Agrawal A, et al. Predicting sensation seeking from dopamine genes. A candidate-system approach. Psychol Sci 2010;21:1282-90.

Dick DM, Smith G, Olausson P, Mitchell SH, Leeman RF, O'Malley SS, et al. Understanding the construct of impulsivity and its relationship to alcohol use disorders. Addict Biol 2010;15:217-26.

DiLillo D, Hayes-Skelton SA, Fortier MA, Perry AR, Evans SE, Messman Moore TL, et al. Development and initial psychometric properties of the Computer Assisted Maltreatment Inventory (CAMI): a comprehensive self-report measure of child maltreatment history. Child Abuse Negl 2010;34:305-17.

Evenden JL. Varieties of impulsivity. Psychopharmacology (Berl) 1999;146:348-61.

Fineberg NA, Potenza MN, Chamberlain SR, Berlin HA, Menzies L, Bechara A, et al. Probing compulsive and impulsive behaviors, from animal models to endophenotypes: a narrative review. Neuropsychopharmacology 2010;35:591-604.

Giegling I, Olgiati P, Hartmann AM, Calati R, Moller HJ, Rujescu D, et al. Personality and attempted suicide. Analysis of anger, aggression and impulsivity. J Psychiatr Res 2009;43:1262-71.

Hamilton KR, Potenza MN. Relations among delay discounting, addictions, and money mismanagement: implications and future directions. Am J Drug Alcohol Abuse 2012;36:434-49.

Hu X, Oroszi G, Chun J, Smith TL, Goldman D, SchuckitMA. An expanded evaluation of the relationship of four alleles to the level of response to alcohol and the alcoholism risk. Alcohol Clin Exp Res 2005;29:8-16.

Huang YY, Cate SP, Battistuzzi C, Oquendo MA, Brent D, Mann JJ. An association between a functional polymorphism in the monoamine oxidase a gene promoter, impulsive traits and early abuse experiences. Neuropsychopharmacology 2004;29:1498-505.

Ioannidis JP, Ntzani EE, Trikalinos TA. "Racial" differences in genetic effects for complex diseases. Nat Genet 2004;36:1312-8.

Jabbi M, Korf J, Kema IP, Hartman C, van der Pompe G, Minderaa RB, et al. Convergent genetic modulation of the endocrine stress response involves polymorphic variations of 5-HTT, COMT and MAOA. Mol Psychiatry 2007;12:483-90.

Jakubczyk A, Wrzosek M, Lukaszkiewicz J, Sadowska-Mazuryk J, Matsumoto H, Sliwerska E, et al. The CC genotype in HTR2A T102C polymorphism is associated with behavioral impulsivity in alcohol-dependent patients. J Psychiatr Res 2012;46:44-9.

Juhasz G, Downey D, HinvestN, Thomas E, Chase D, Toth ZG, et al. Risk-taking behavior in a gambling task associated with variations in the tryptophan hydroxylase 2 gene: relevance to psychiatric disorders. Neuropsychopharmacology 2010;35:1109-19.

Kuntsi J, McLoughlin G, Asherson P. Attention deficit hyperactivity disorder. Neuromolecular Med 2006;8:461-84.

Lemonde S, Turecki G, Bakish D, Du L, Hrdina PD, Bown CD, et al. Impaired repression at a 5hydroxytryptamine $1 \mathrm{~A}$ receptor gene polymorphism associated with major depression and suicide. J Neurosci 2003;23:8788-99. 
STOLTENBERG, CHRist, AND Highland,

PROGRESS IN NEURO-PSYCHOPHARMACOLOGY E BIOLOGICAL PSYCHIATRY 39 (2012)

Liu L, Guan LL, Chen Y, Ji N, Li HM, Li ZH, et al. Association analyses of MAOA in Chinese Han subjects with attention-deficit/hyperactivity disorder: family-based association test, case-control study, and quantitative traits of impulsivity. Am J Med Genet B Neuropsychiatr Genet 2011; 156B:737-48.

Lopez de Lara C, Brezo J, Rouleau G, Lesage A,DumontM, AldaM, et al. Effect of tryptophan hydroxylase-2 gene variants on suicide risk in major depression. Biol Psychiatry 2007;62:72-80.

Lung FW, Tzeng DS, Huang MF, Lee MB. Association of the MAOA promoter uVNTR polymorphism with suicide attempts in patients with major depressive disorder. BMC Med Genet 2011; 12:74.

Mackay TF, Stone EA, Ayroles JF. The genetics of quantitative traits: challenges and prospects. Nat Rev Genet 2009;10:565-77.

Manchia M, Zai CC, Squassina A, Vincent JB, De Luca V, Kennedy JL. Mixture regression analysis on age at onset in bipolar disorder patients: investigation of the role of serotonergic genes. Eur Neuropsychopharmacol 2010;20:663-70.

McCrory E, De Brito SA, Viding E. The impact of childhood maltreatment: a review of neurobiological and genetic factors. Front Psychiatry 2011;2:48.

Murphy DL, Moya PR. Human serotonin transporter gene (SLC6A4) variants: their contributions to understanding pharmacogenomic and other functional GxG and GxE differences in health and disease. Curr Opin Pharmacol 2011;11:3-10.

Nakamura M, Ueno S, Sano A, Tanabe H. The human serotonin transporter gene linked polymorphism (5-HTTLPR) shows ten novel allelic variants. Mol Psychiatry 2000;5:32-8.

New AS, Gelernter J, Goodman M, Mitropoulou V, Koenigsberg H, Silverman J, et al. Suicide, impulsive aggression, and HTR1B genotype. Biol Psychiatry 2001;50:62-5.

Nishizawa S, Benkelfat C, Young SN, Leyton M, Mzengeza S, de Montigny C, et al. Differences between males and females in rates of serotonin synthesis in human brain. Proc Natl Acad Sci U S A 1997;94:5308-13.

Niv S, Tuvblad C, Raine A, Wang P, Baker LA. Heritability and longitudinal stability of impulsivity in adolescence. Behav Genet 2012;42:378-92.

Nugent NR, Tyrka AR, Carpenter LL, Price LH. Gene-environment interactions: early life stress and risk for depressive and anxiety disorders. Psychopharmacology (Berl) 2011;214:175-96.

Oades RD, Lasky-Su J, Christiansen H, Faraone SV, Sonuga-Barke EJ, Banaschewski T, et al. The influence of serotonin- and other genes on impulsive behavioral aggression and cognitive impulsivity in children with attention-deficit/hyperactivity disorder (ADHD): findings from a familybased association test (FBAT) analysis. Behav Brain Funct 2008;4:48.

Paaver M, Nordquist N, Parik J, Harro M, Oreland L, Harro J. Platelet MAO activity and the 5-HTT gene promoter polymorphism are associated with impulsivity and cognitive style in visual information processing. Psychopharmacology (Berl) 2007;194:545-54.

Paaver M, Kurrikoff T, Nordquist N, Oreland L, Harro J. The effect of 5-HTT gene promoter polymorphism on impulsivity depends on family relations in girls. Prog Neuropsychopharmacol Biol Psychiatry 2008;32:1263-8.

Parsons MJ, D'Souza UM, Arranz MJ, Kerwin RW, Makoff AJ. The -1438A/G polymorphism in the 5-hydroxytryptamine type 2A receptor gene affects promoter activity. Biol Psychiatry 2004;56: 406-10.

Pattij T, Vanderschuren LJ. The neuropharmacology of impulsive behaviour. Trends Pharmacol Sci 2008;29:192-9. 
STOLTENBERG, CHRist, AND Highland,

Patton JH, Stanford MS, Barratt ES. Factor structure of the Barratt impulsiveness scale. J Clin Psychol 1995;51:768-74.

Perez-Rodriguez MM, Weinstein S, New AS, Bevilacqua L, Yuan Q, Zhou Z, et al. Tryptophanhydroxylase 2 haplotype association with borderline personality disorder and aggression in a sample of patients with personality disorders and healthy controls. J Psychiatr Res 2010;44:1075-81.

Peterson RE, Maes HH, Holmans P, Sanders AR, Levinson DF, Shi J, et al. Genetic risk sum score comprised of common polygenic variation is associated with body mass index. Hum Genet 2011; 129:221-30.

Reuter M, Ott U, Vaitl D, Hennig J. Impaired executive control is associated with a variation in the promoter region of the tryptophan hydroxylase 2 gene. J Cogn Neurosci 2007;19:401-8.

Robbins TW, Gillan CM, Smith DG, de Wit S, Ersche KD. Neurocognitive endophenotypes of impulsivity and compulsivity: towards dimensional psychiatry. Trends Cogn Sci 2012;16:81-91.

Rujescu D, Giegling I, Sato T, Moller HJ. Lack of association between serotonin 5-HT1B receptor gene polymorphism and suicidal behavior. Am J Med Genet B Neuropsychiatr Genet 2003;116B:69-71.

Sabol SZ, Hu S, Hamer D. A functional polymorphism in the monoamine oxidase A gene promoter. Hum Genet 1998;103:273-9.

Saiz PA, Garcia-Portilla MP, Florez G, Arango C, Corcoran P, Morales B, et al. Differential role of serotonergic polymorphisms in alcohol and heroin dependence. Prog Neuropsychopharmacol Biol Psychiatry 2009;33:695-700.

Saiz PA, Garcia-Portilla MP, Herrero R, Arango C, Corcoran P, Morales B, et al. Interactions between functional serotonergic polymorphisms and demographic factors influence personality traits in healthy Spanish Caucasians. Psychiatr Genet 2010;20:171-8.

Saleptsi E, Bichescu D, Rockstroh B, Neuner F, Schauer M, Studer K, et al. Negative and positive childhood experiences across developmental periods in psychiatric patients with different diagnoses - an explorative study. BMC Psychiatry 2004;4:40.

Salo J, Pulkki-Raback L, Hintsanen M, Lehtimaki T, Keltikangas-Jarvinen L. The interaction between serotonin receptor $2 \mathrm{~A}$ and catechol-O-methyltransferase gene polymorphisms is associated with the novelty-seeking subscale impulsiveness. Psychiatr Genet 2010;20:273-81.

Sato H, Skelin I, Diksic M. Chronic buspirone treatment decreases 5-HT1B receptor densities and the serotonin transporter but increases the density of 5-HT2A receptors in the bulbectomized rat model of depression: an autoradiographic study. Brain Res 2010;1345:28-44.

Shenassa ED, Paradis AD, Dolan SL, Wilhelm CS, Buka SL. Childhood impulsive behavior and problem gambling by adulthood: a 30-year prospective community-based study. Addiction 2012;107: 160-8.

Shiffman D, Rowland CM, Sninsky JJ, Devlin JJ. Polymorphisms associated with coronary heart disease: better by the score. Curr Opin Mol Ther 2006;8:493-9.

Soloff PH, Price JC, Mason NS, Becker C, Meltzer CC. Gender, personality, and serotonin-2A receptor binding in healthy subjects. Psychiatry Res 2010;181:77-84.

Stoltenberg SF. Epistasis among presynaptic serotonergic system components. Behav Genet 2005;35: 199-209.

Stoltenberg SF, Nag P. Description and validation of a dynamical systems model of presynaptic serotonin function: genetic variation, brain activation and impulsivity. Behav Genet 2010;40:262-79.

Stoltenberg SF, Glass JM, Chermack ST, Flynn HA, Li S,Weston ME, et al. Possible association between response inhibition and a variant in the brain-expressed tryptophan hydroxylase-2 gene. Psychiatr Genet 2006;16:35-8. 
STOLTENBERG, CHRist, AND Highland,

PROGRESS IN NEURO-PSYCHOPHARMACOLOGY E BIOLOGICAL PSYCHIATRY 39 (2012)

Stoltenberg SF, Lehmann MK, Anderson C, Nag P, Anagnopoulos C. Serotonin transporter (5-HTTLPR) genotype and childhood trauma are associated with individual differences in decision making. Front Genet 2011a;2.

Stoltenberg SF, Lehmann MK, Christ CC, Hersrud SL, Davies GE. Associations among types of impulsivity, substance use problems and neurexin-3 polymorphisms. Drug Alcohol Depend 2011b; 119:e31-8.

Stoltenberg SF, Anderson C, Nag P, Anagopoulos C. Association between the serotonin transporter triallelic genotype and eating problems is moderated by the experience of childhood trauma in women. Int J Eat Disord 2012;45:492-500.

Swann AC. Mechanisms of impulsivity in bipolar disorder and related illness. Epidemiol Psychiatr Sci 2010;19:120-30.

Templeton AR. Epistasis and complex traits. In: Wolf JB, Brodie ED, WadeMJ, editors. Epistasis and the evolutionary process. New York: Oxford University Press; 2000. p. 41-57.

Tikkanen R, Ducci F, Goldman D, Holi M, Lindberg N, Tiihonen J, et al. MAOA alters the effects of heavy drinking and childhood physical abuse on risk for severe impulsive acts of violence among alcoholic violent offenders. Alcohol Clin Exp Res 2010;34: 853-60.

Tops M, Russo S, Boksem MA, Tucker DM. Serotonin: modulator of a drive to withdraw. Brain Cogn 2009;71:427-36.

Uher R, Caspi A, Houts R, Sugden K, Williams B, Poulton R, et al. Serotonin transporter gene moderates childhood maltreatment's effects on persistent but not single-episode depression: replications and implications for resolving inconsistent results. J Affect Disord 2011;135:56-65.

Varga G, Szekely A, Antal P, Sarkozy P, Nemoda Z, Demetrovics Z, et al. Additive effects of serotonergic and dopaminergic polymorphisms on trait impulsivity. Am J Med Genet B Neuropsychiatr Genet 2012;159B:281-8.

Viikki M, Huuhka K, Leinonen E, Illi A, Setala-Soikkeli E, Huuhka M, et al. Interaction between two HTR2A polymorphisms and gender is associated with treatment response in MDD. Neurosci Lett 2011;501:20-4.

Villafuerte SM, Vallabhaneni K, Sliwerska E, McMahon FJ, Young EA, Burmeister M. SSRI response in depression may be influenced by SNPs in HTR1B and HTR1A. Psychiatr Genet 2009;19:281-91.

Wagner S, Baskaya O, Lieb K, Dahmen N, Tadic A. The 5-HTTLPR polymorphism modulates the association of serious life events (SLE) and impulsivity in patients with Borderline Personality Disorder. J Psychiatr Res 2009;43:1067-72.

Waxman SE. A systematic review of impulsivity in eating disorders. Eur Eat Disord Rev 2009;17:408-25.

Wendland JR, Martin BJ, Kruse MR, Lesch KP, Murphy DL. Simultaneous genotyping of four functional loci of human SLC6A4, with a reappraisal of 5-HTTLPR and rs25531. Mol Psychiatry 2006; 11:224-6.

Williams RB, Marchuk DA, Gadde KM, Barefoot JC, Grichnik K, Helms MJ, et al. Serotonin-related gene polymorphisms and central nervous system serotonin function. Neuropsychopharmacology 2003;28:533-41.

Winstanley CA. The utility of rat models of impulsivity in developing pharmacotherapies for impulse control disorders. Br J Pharmacol 2011;164:1301-21.

Wrzosek M, Lukaszkiewicz J, Serafin P, Jakubczyk A, Klimkiewicz A, Matsumoto H, et al. Association of polymorphisms in HTR2A, HTR1A and TPH2 genes with suicide attempts in alcohol dependence: a preliminary report. Psychiatry Res 2011;190:149-51.

Zupanc T, Pregelj P, Tomori M, Komel R, Paska AV. TPH2 polymorphisms and alcohol-related suicide. Neurosci Lett 2011;490:78-81. 